\title{
Results from Three Municipal Hospitals Regarding Radical Cystectomy on Elderly Patients
}

\author{
Matthias May, Stephanie Fuhrer, Kay-P. Braun, Sabine Brookman-Amissah, Willi Richter, \\ Bernd Hoschke, Horst Vogler, Michael Siegsmund
}

Department of Urology (MM, BH, SF, KPB, SBA), Carl-Thiem Hospital, Cottbus, Department of

Urology (MS,WR), Vivantes-Clinic Am Urban, Berlin and Department of Urology $(H V)$,

Vivantes-Clinic Friedrichshain, Berlin, Germany

\begin{abstract}
Objective: Radical cystectomy is the standard treatment for invasive bladder carcinoma in elderly patients at major surgical centers. As yet no data are available as to the question whether radical surgery on the genitourinary tract of patients over 75 can also be carried out at municipal hospitals with comparable intra and postoperative morbidity, and respective mortality.

Materials and Methods: 452 radical cystectomies and urinary diversions as ileum conduits or ileum neobladders due to transitional cell carcinoma were carried out at three municipal hospitals between 1992 and 2004. At the time of the surgery, 44 patients $(9.7 \%$ ) were $\geq 75$ (75-84) (Group-1), by comparison 408 patients were younger than 75 (35-74) (Group-2). Comparisons are to be made between the groups for 30 day mortality, 30 day reoperation rate, early complication rate ( $\leq 3$ months), late complication rate (> 3 months), progression-free survival, and overall survival. The results are to be discussed in view of the international literature. Mean follow-up was 49 months (median: 38 months).

Results: The perioperative mortality in Group- 1 was $2.3 \%$ compared to $2.5 \%$ in Group- $2(\mathrm{p}=0.942)$. There was no significant difference in the perioperative mortality with regard to the different case load of the evaluated hospital. There were no significant group differences regarding the 30 day reoperation rate, early and late complications. Progression-free and overall survival of all patients after 5 years was $56.1 \%$ and $53.6 \%$ respectively; here again the differences between the age groups was not significant $(\mathrm{p}=0.384$ and $\mathrm{p}=0.210$ ). Our results for patients $\geq 75$ do not differ from the published data of large clinics with a high cystectomy frequency.

Conclusions: Our data confirm that radical cystectomy on elderly patients can also be carried out in municipal hospitals with acceptable mortality and morbidity rates. Of prime importance is a careful patient selection based on comorbidity scores and possibly geriatric assessment.
\end{abstract}

Key words: bladder neoplasms; cystectomy; age; ileum; survival Int Braz J Urol. 2007; 33: 764-76

\section{INTRODUCTION}

The highest incidence of transitional cell carcinoma of the bladder is in the 7th decade. Around $20-40 \%$ of transitional cell carcinomas consist of a muscle invasion, initially or in progress; standard treatment continues to be radical cystectomy (RC) with urinary diversion. Improvements in medical care have produced a continuous rise in life expectancy in Europe. In 2025, the proportion of over 65 -year-olds 
worldwide will rise from 390 to 800 million and will be around $10 \%$ of the total population $(1,2)$. Consequently, $\mathrm{RC}$ in old age will become increasingly important. By comparison, $\mathrm{RC}$ with urinary diversion is the most invasive surgery in the urogenital tract with accepted perioperative mortality between 1 and $8 \%$ (3-5). According to a Dutch analysis of patients $\geq 75$ with tumor disorders, $73 \%$ of patients had relevant ancillary disorders, $20 \%$ of these even had two or more additional diagnoses (6).

Consistent advances in surgical technique, anesthesia of patients and postoperative intensive medical care also makes RC possible for the elderly (7). Even so, a positive benefit/risk ratio should always be present here. Especially in elderly patients it must be ensured that treatment does not produce even more problems than those from the disease. In recent years, various university clinics have presented their positive experiences with RC on carefully selected elderly patients (8-33). At present, no studies are available in the international bibliography that indicates that this surgery in elderly patients is possible in an acceptable quality at municipal hospitals without a high level of annual cystectomies.

The goals of the current study are to update our experience in a rigorously defined population from three municipal hospitals and to compare the outcomes between younger $(<75$ years) and older patients $(\geq$ 75 years). Especially, we sought to explore the influence of age on pathologic characteristics, overall survival rates, disease recurrence-free survival rates, complication rates, operative mortality and length of hospital stay.

\section{MATERIALS AND METHODS}

All RC carried out between February 1992 and September 2004 at the Urological Departments of the Vivantes-Clinics Berlin-Friedrichshain ( $n=268$; mean annual case load: 21.5) and Berlin-Am Urban ( $\mathrm{n}=196$; mean annual case load: 15.5) and at the Carl-Thiem Hospital Cottbus ( $\mathrm{n}=54$; mean annual case load: 4.5) were listed retrospectively. For this study, 66 patients were excluded from the total of 518 consecutive cystectomies. Reasons for this were the presence of gynecological malignancies where the cystectomy was carried out during frontal exenteration $(\mathrm{n}=25)$ and palliative cystectomy with documented distant metastasis $(n=12) .29$ patients had non-urothelial carcinoma of the bladder (14 had adenocarcinoma, 9 had squamous cell carcinoma, 5 had mesenchymal tumor and one had a neuro-endocrine tumor), which were also disregarded in this study.

Consequently, 452 patients with primary transitional cell carcinoma of the bladder were evaluated, who had been subjected to curatively intended RC with simultaneous bilateral pelvic lymphadenectomy. The study group consisted of 347 male $(76.8 \%)$ and 105 female (23.2\%) patients (ratio 3.3:1). The mean patient age when cystectomy took place was 64.3 (3580 ) with a median of 64.9. When surgery took place, 44 patients $(9.7 \%)$ were $\geq 75$ (75-84) (Group-1), by comparison, 408 patients were younger than 75 (3574) (Group-2).

The indication for radical cystectomy consisted of the muscle invasive tumor stage without distant metastases $(\mathrm{n}=338)$ as well as of BCG-refractory, undifferentiated tumor recurrence (Ta, $\mathrm{T} 1$, Tis) $(\mathrm{n}=91)$. In 23 cases, radical cystectomy took place due to a rTa/1(m), G2 tumor that could not be controlled in TUR-B. None of the assessed patients received neo-adjuvant chemotherapy.

Local tumor stage (pT-stage) and the lymph node status were described according to the TNM classification of the UICC (6th edition, 2002) (34). Pathological stages were defined with organ confined and lymph node negative tumors (pT0, pTis, pTa-pT2b), extravesical growing and lymph node negative tumors (pT3a-pT4b) as well as the lymph node positive tumors (pT0-pT4, pN+).

The preoperative procedures included physical examination, blood tests, determination of renal and hepatic function as well as the metabolic status. Spirometry, exercise ECG, echocardiography and coronary angiography were only carried out to clarify special questions. A CT scan of the thorax and abdomen as well as an x-ray of the thorax was done on all patients. Exceptional cases also involved bone scintigraphy. Patients were admitted to hospital 48 hours before surgery; mechanical intestinal preparation, intravenous fluid substitution and blood transfusion for 
anemia followed. All patients were given a perioperative, prophylactic wide spectrum antibiotic.

A nasogastric tube, intra-arterial pressure measurement and a central venous catheter were placed intraoperatively. On all patients a thoracic peridural catheter (PDC) was preferred, however only placement of a lumbar PDC frequently took place (n $=221$ ). For men, the surgery consisted of a radical cystoprostatectomy and for women of a radical urethrocystectomy including the uterus and the anterior vagina. Appendectomy (where not yet done) and bilateral pelvic lymphadenectomy were carried out on all patients. The urinary diversion after RC took place as an ileum conduit $(\mathrm{n}=260,57.5 \%)$ or as ileum neobladder $(\mathrm{n}=192,42.5 \%)$. Irrespective of the urinary diversion, all ureters were catheterized.

All patients received direct post surgical monitoring on the anesthesiology intensive care unit. The nasogastric tube was removed when food was provided again and reflux had ceased. Prophylactic anticoagulation continued as planned for 4 weeks. Removal of the ureter stent took place after 10-14 days.

During the initial two postoperative years, all patients received after care at 3 monthly intervals, which was extended to 6 months from the third postoperative year onwards. Annual checkups were carried out after the fifth postoperative year. These checkups involved a review of total body status, abdominal sonography and thorax X-ray as well as determining the lab chemical parameters. An excretory urogram was carried out after 3 months and then annually, the use of CT, MRI and bone scintigraphy depended on the individual facts.

The perioperative mortality (every death within 30 days of cystectomy), the 30 day reoperation rate, early complications (every complication within 3 months of cystectomy) and late complications (> 3 months after cystectomy) were noted. Also recorded was the intraoperative blood loss, the operating time, the blood transfusion rate and the inpatient period as well as the general preoperative status according to the criteria of the American Society of Anesthesiologists (ASA) (35).

The oncological progress was determined as progression-free survival and as overall survival. Progression-free survival represents the time between radical cystectomy and initial finding of tumor relapse; whereby patients who died without tumor progress were censored at the time of death. Overall survival consists of the time from radical cystectomy until death, irrespective of cause. All patients alive when the study ended were censored according to their follow-up.

The mean observation time for the complete patient group was 49 months with a maximum followup of 13 years and 2 months. $83 \%$ of all patients had a $\geq 12$ month observation period; the aftercare update took place in June 2005.

The survival probability and progression rate was determined with the Kaplan-Meier method. The Log-Rank test was used for checking the differences in the survival rates between the groups. The MannWhitney, respectively Chi-square test determined significant differences in the distribution of patient characteristics and tumor stages. A difference was defined with a significance level of $\mathrm{p} \leq 0.05$.

\section{RESULTS}

Table-1 shows the demographic factors, patient characteristics and the distribution of study criteria (total and per group) perioperative mortality, 30day reoperation rate, early complications, late complications, intra-operative blood loss, operating time, blood transfusion rate and the length of stay in hospital. Significant differences could only be shown in the gender ratio and the type of urinary diversion, whereby Group-1 patients had a proportionately higher female ratio $(\mathrm{p}=0.038)$ and were provided relatively more frequently with an ileum conduit $(86.4 \%$ against $54.4 \%, \mathrm{p}<0.001)$. No differences were shown in the criteria in Table-1 for the case load, for example, the hospital with the lowest cystectomy frequency (on average 4.5 per annum) had a perioperative mortality of $0 \%$. In Group-1 there was just one perioperative death (2.3\%); an 83-year-old patient died on the 12th postoperative day from a fulminant pulmonary embolism. Early complications were noted on 180 patients (39.8\%). These consisted primarily of asymptomatic hydronephrosis, mild forms of disturbed wound healing and postoperative intestinal atony, which did not need any surgical intervention. During the period un- 
Table 1 - Demographic information, patient characteristics and clinical outcome of 452 patients after radical cystectomy (total and stratified according to age groups). The p-value refers to the comparison between the age groups.

\begin{tabular}{lcccc}
\hline Factors & $\begin{array}{c}\text { Total Group } \\
\mathrm{n}=452(\%)\end{array}$ & $\begin{array}{c}\text { Group-1 } \\
\mathrm{n}=44(\%)\end{array}$ & $\begin{array}{c}\text { Group-2 } \\
\mathrm{n}=408(\%)\end{array}$ & $\begin{array}{c}\text { p Value } \\
0.033\end{array}$ \\
\hline Mean follow-up (months) & 49.1 & 36.4 & 50.1 & $<0.001$ \\
Patient age (years) & & & & \\
$\quad$ Median & 65.0 & 77.6 & 63.7 & \\
$\quad$ Mean ( \pm SD) & $64.3(8.7)$ & $78.3(2.8)$ & $62.7(7.8)$ & \\
$\quad$ Range & $35-84$ & $75-84$ & $35-74$ & 0.038 \\
Gender ratio (M; F) & $3.3: 1$ & $1.8: 1$ & $3.6: 1$ & $<0.001$ \\
Urinary diversion & & & & \\
$\quad$ Ileum conduit & $260(57.5)$ & $38(86.4)$ & $222(54.4)$ & 0.942 \\
$\quad$ Ileal neobladder & $192(42.5)$ & $6(13.6)$ & $186(45.6)$ & 0.812 \\
Perioperative mortality & $11(2.4)$ & $1(2.3)$ & $10(2.5)$ & 0.866 \\
30-day Re-OP rate & $24(5.3)$ & $2(4.5)$ & $22(5.4)$ & 0.621 \\
Early complications & $180(39.8)$ & $17(38.6)$ & $163(40.0)$ & \\
Late complications & $159(35.2)$ & $17(38.6)$ & $142(34.8)$ & $<0.001$ \\
ASA Score & & & & \\
$\quad$ Score 1 & $45(10)$ & 0 & $45(11)$ & \\
Score 2 & $211(46.7)$ & $14(31.8)$ & $197(48.3)$ & \\
Score 3 & $170(37.6)$ & $26(59.1)$ & $144(35.3)$ & \\
Score 4 & $26(5.7)$ & $4(9.1)$ & $22(5.4)$ & \\
Mean blood loss (mL) \pm SD & $933 \pm 523$ & $987 \pm 957$ & $928 \pm 453$ & 0.471 \\
Mean number of EC \pm SD & $3.39 \pm 2.3$ & $3.84 \pm 3$ & $3.35 \pm 2.2$ & 0.171 \\
Mean OP time (min.) \pm SD & $279 \pm 59$ & $266 \pm 54$ & $281 \pm 60$ & 0.128 \\
Mean in patient time (d) \pm SD & $22.2 \pm 5.1$ & $27.5 \pm 10$ & $21.6 \pm 3.9$ & $<0.001$ \\
\hline
\end{tabular}

$E C=$ erythrocyte concentrates; $S D=$ standard deviation.

der review, late complications were observed on 159 patients $(35.2 \%)$. These mainly consisted of hydronephrosis and mild metabolic acidosis. The 30 day reoperation rate was $5.3 \%$ (24 patients, Table-2). There were no significant differences between the groups where the complication and reoperation rate were concerned.

There were no significant differences between the age groups in the pathological tumor stage (Table-3). Progression-free and overall survival of all 452 patients after 5 years was $56.1 \%$ and $53.6 \%$, respectively (Table-3). Only 65\% lived progression-free after 2 years, so that the majority of tumor progressions were noted in the initial two years after RC. In the initial 36 months after surgery, $36 \%$ of patients died, most as a consequence of progressed carcinoma of the bladder. There were no significant differences in overall ( $\mathrm{p}=0.210$, Figure-1) and progression-free survival ( $p=0.384$, Figure-2) between the age groups.

\section{COMMENTS}

In various publications from the 1980's, RC and urinary diversion on elderly patients had a high perioperative mortality exceeding $10 \%(9,11,17)$. In a study by Thomas and Riddle, with $12 \%$, it was virtually twice as much for patients over 65 than for patients under 65 years (11). Over the last 20 years, this impression has changed considerably due to improved anesthesiology and intensive therapy capabilities $(7,36)$. In 12 studies over the past 10 years, a $0-7.3 \%$ 
Table 2 - Re-operation rate (30 days) for each age group. The p-value refers to the comparison between the age groups.

\begin{tabular}{lcccc}
\hline Cause of Re-operation & $\begin{array}{c}\text { Total Group } \\
\mathrm{n}=452(\%)\end{array}$ & $\begin{array}{c}\text { Group-1 } \\
\mathrm{n}=44(\%)\end{array}$ & $\begin{array}{c}\text { Group-2 } \\
\mathrm{n}=408(\%)\end{array}$ & p Value \\
\hline Small bowel obstruction (ileus) & $13(2.9)$ & $1(2.3)$ & $12(2.9)$ & 0.801 \\
Fascial dehiscence & $2(0.4)$ & 0 & $2(0.5)$ & 0.642 \\
Urinary leak / urinary fistula & $2(0.4)$ & 0 & $2(0.5)$ & 0.642 \\
Hemorrhage /bleeding & $3(0.7)$ & 0 & $3(0.7)$ & 0.568 \\
Enteric fistula & $3(0.7)$ & $1(2.3)$ & $2(0.5)$ & 0.167 \\
Pulmonary embolus & $1(0.2)$ & 0 & $1(0.2)$ & 0.742 \\
All & $24(5.3)$ & $2(4.5)$ & $22(5.4)$ & 0.812 \\
\hline
\end{tabular}

Table 3 - Pathological parameters and survival rates of 452 patients following radical cystectomy (total and stratified according to age groups). The p-value refers to the comparison between the age groups.

\begin{tabular}{lllcc}
\hline Factors & $\begin{array}{l}\text { Total Group } \\
\mathrm{n}=452(\boldsymbol{\%})\end{array}$ & $\begin{array}{l}\text { Group-1 } \\
\mathrm{n}=44(\%)\end{array}$ & $\begin{array}{l}\text { Group-2 } \\
\mathrm{n}=408(\%)\end{array}$ & p Value \\
\hline $\begin{array}{l}\text { Mean follow-up (months) } \\
\text { Pathological tumor stage }\end{array}$ & 49.1 & 36.4 & 50.1 & 0.033 \\
$\quad$ pT0-pT2, pN0 & $213(47.1)$ & $20(45.5)$ & $193(47.3)$ & 0.725 \\
pT3-pT4, pN0 & $112(24.8)$ & $13(29.5)$ & $99(24.3)$ & \\
pN+ & $127(28.1)$ & $11(25.0)$ & $116(28.4)$ & \\
3 years total survival (\%) & 62.9 & 56.7 & 63.6 & 0.210 \\
3 years PF survival (\%) & 59.6 & 55.8 & 60.0 & 0.384 \\
5 years total survival (\%) & 53.6 & 49.1 & 54.1 & 0.210 \\
5 years PF survival (\%) & 56.1 & 49.6 & 56.7 & 0.384 \\
\hline
\end{tabular}

PF = progression-free.

perioperative mortality was shown for RC on patients over 70 (Table-4) (22-33). Although no deaths occurred in 5 of these studies, 20 patients died in the other 7. One perioperative death occurred amongst the 44 elderly patients in our study (Group-1), due to fulminant pulmonary embolism despite heparinization. The postoperative early complications rate in the stated current studies was between $27 \%$ and $74 \%$ (22-33). In most cases, the complications were not directly connected to the operation. Urinary infections, respectively pyelonephritis (0-32\%), pulmonary infections ( 0 $20 \%)$, cardiovascular complications (6-38\%) and amentia state (11-20\%) occurred most frequently.
Prolonged obstipation (8-35\%) and disturbed wound healing (6-24\%) were prime factors for complications arising in direct relationship to the operation (22-33). When comparing morbidity rates for cystectomies on younger and elderly patients, most authors were unable to detect any significant difference (Table-4). The rate of late complications varies in the already quoted current studies between 12 and 35\% (22-33). These consist primarily of surgical complications, whereby the most frequent were ileus symptoms, incisional hernias and incontinence after orthotopic bladder replacement. This is comparable with the situation of younger patients, where problems primarily arise long- 
Table 4 - Bibliography overview of studies concerning radical cystectomy on elderly patients.

\begin{tabular}{|c|c|c|c|c|c|c|}
\hline $\begin{array}{l}\text { Definition of } \\
\text { Elderly Patients } \\
\text { (years) }\end{array}$ & $\begin{array}{l}\text { Number of } \\
\text { Patients }\end{array}$ & $\begin{array}{l}\text { Mortality } \\
\text { Rate (\%) }\end{array}$ & $\begin{array}{c}\text { Differences to } \\
\text { Younger Age } \\
\text { Groups }\end{array}$ & $\begin{array}{c}\text { Early and Late } \\
\text { Complication } \\
\text { Rate }(\%)\end{array}$ & $\begin{array}{c}\text { Differences to } \\
\text { Younger Age } \\
\text { Groups }\end{array}$ & Author (year) \\
\hline $70-80$ & 25 & 0.0 & - & 40.0 & - & Kursh (1977) (8) \\
\hline$\geq 70$ & 24 & 18.0 & - & $54.0 /-$ & - & Zingg (1980) (9) \\
\hline$\geq 80$ & 19 & 5.3 & - & $47.0 /-$ & - & Zincke(1982)(10) \\
\hline$\geq 65$ & 41 & 12.0 & Yes & - & - & Thomas (1982) (11) \\
\hline$\geq 70$ & 28 & 0.0 & - & - & - & Drago (1983) (12) \\
\hline$\geq 80$ & 9 & 0.0 & No & $67.0 *$ & Yes & Tachibana (1983) (13) \\
\hline$\geq 65$ & 77 & 3.9 & - & $34.0 /-$ & - & Skinner (1984) (14) \\
\hline$\geq 80$ & 9 & 0.0 & - & 33.0 & - & Ogawa(1985) (15) \\
\hline$\geq 70$ & 38 & 5.3 & No & 34.0 & No & Wood (1987) (16) \\
\hline$\geq 80$ & 7 & 14.0 & - & - & - & Orihuela(1987)(17) \\
\hline$>70$ & 39 & 2.5 & - & $7.7^{\#}$ & - & Bollack (1989) (18) \\
\hline$\geq 70$ & 42 & 9.5 & No & - & No & Leibovitch (1993) (19) \\
\hline$\geq 75$ & 21 & 9.5 & No & $28.0 / 48.0$ & No & Navon (1995) (20) \\
\hline$\geq 70$ & 47 & - & - & - & - & Koch (1996) (21) \\
\hline$\geq 80$ & 44 & 4.5 & - & 51.0 & - & Stroumbakis (1997)(22) \\
\hline$\geq 70$ & 404 & 2.8 & No & $29.0 / 12.4$ & No & Figueroa (1998) (23) \\
\hline$\geq 70$ & 33 & 0.0 & No & - & - & Rosario (2000) (24) \\
\hline$>80$ & 36 & 0.0 & - & 61.0 & - & Lance (2001) (25) \\
\hline$\geq 75$ & 44 & 0.0 & - & $28.0 / 9.0$ & - & Chang (2001) (26) \\
\hline$\geq 75$ & 25 & 4.0 & - & $64.0 / 24.0$ & - & Gamé(2001)(27) \\
\hline$\geq 75$ & 12 & 0.0 & No & $47.1 / 33.3$ & No & Saika (2001) (28) \\
\hline$\geq 80$ & 27 & - & Yes & $74.1 /-$ & - & Gschwend (2004) (29) \\
\hline$\geq 70$ & 41 & 7.3 & No & $29.7 / 12.0$ & No & Gupta (2004) (30) \\
\hline$\geq 75$ & 54 & 1.9 & - & $40.7 / 35.2$ & - & Deliveliotis (2005) (31) \\
\hline$\geq 75$ & 46 & 4.3 & - & $22.0 / 11.0$ & - & Zebic (2005) (32) \\
\hline$\geq 80$ & 50 & 0.0 & No & $30.0 / 14.0$ & No & Clark (2005) (33) \\
\hline$\geq 75$ & 44 & 2.3 & No & $38.6 / 38.6$ & No & Present data \\
\hline
\end{tabular}

$*=$ dementia rate $;=$ reoperation rate $; \dagger=$ surgical complications only.

term with regard to urinary diversion. The indication for continent, orthotopic urinary diversion was strictly specified in the assessed hospitals for patients over 75. Apart from the clearly defined non-oncological contraindications for orthotopic bladder replacement (renal insufficiency, cerebrovascular insufficiency), a raised anesthesiology risk profile $(\mathrm{ASA} \geq 3)$ was seen as a relative contraindication in this age group since, apart from the operating time, the morbidity is similarly increased by the related urinary diversion.

Post-operative transitory psychotic syndromes were frequently reported in relation to major surgical interventions (37). In our study, postoperative disorientation was observed on 3 patients $(6.8 \%)$ in Group1 , which was clearly below the rates reported in the bibliography by up to $30 \%(14,22,23,27,30)$. Careful intraoperative monitoring (preventing ischemia and hypoxia), adequate postoperative analgesia and good patient selection using comorbidity scores and, possibly, geriatric assessment, assist in preventing postoperative transitory psychosis. The preoperative cardio pulmonary risk assessment, the Charlson comorbidity score (38) and the ASA score (34) appear suitable for identification of a RC patient, from amongst the 


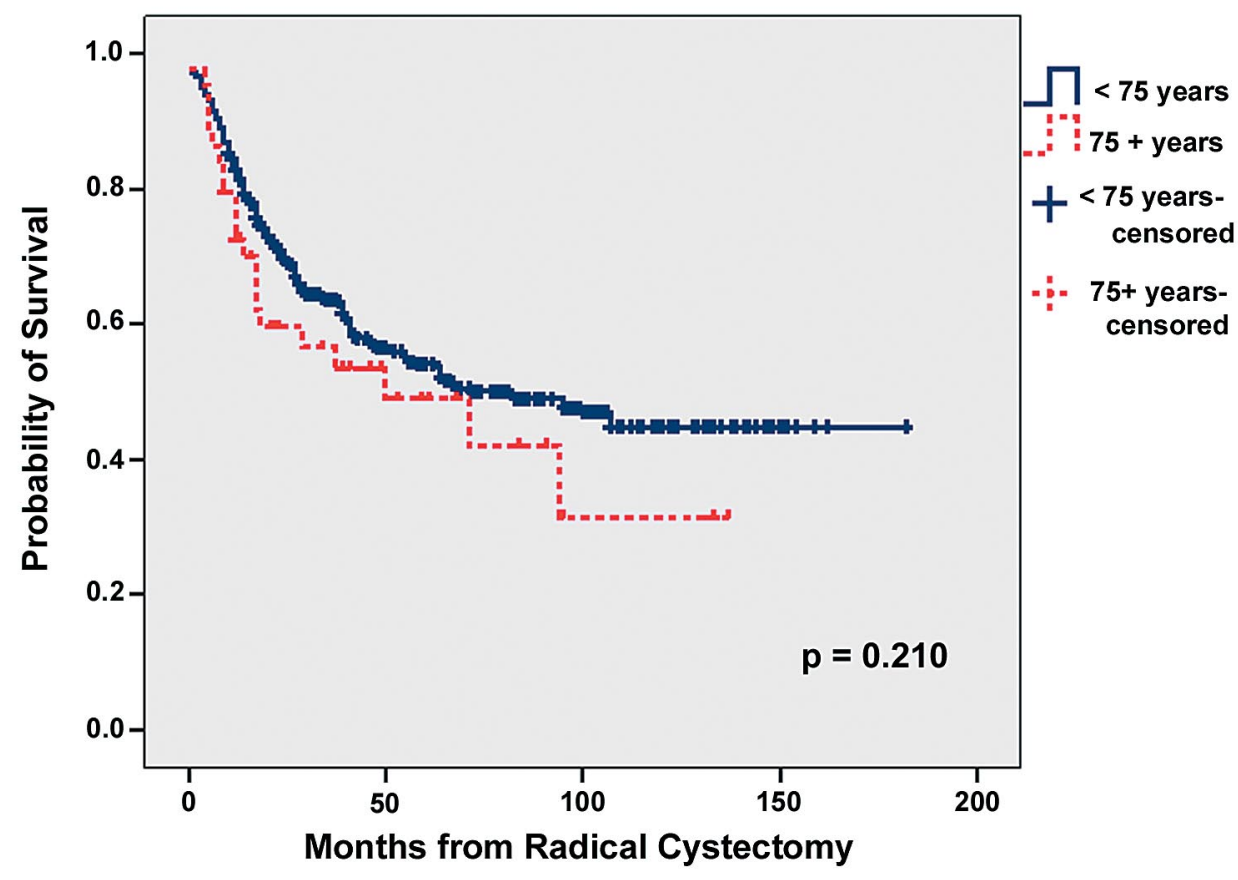

Figure 1-Overall survival of 452 patients after radical cystectomy for a transitional cell carcinoma of the bladder, stratified according to age groups ( $\geq 75$ against $<75$ years, Kaplan-Meier method).

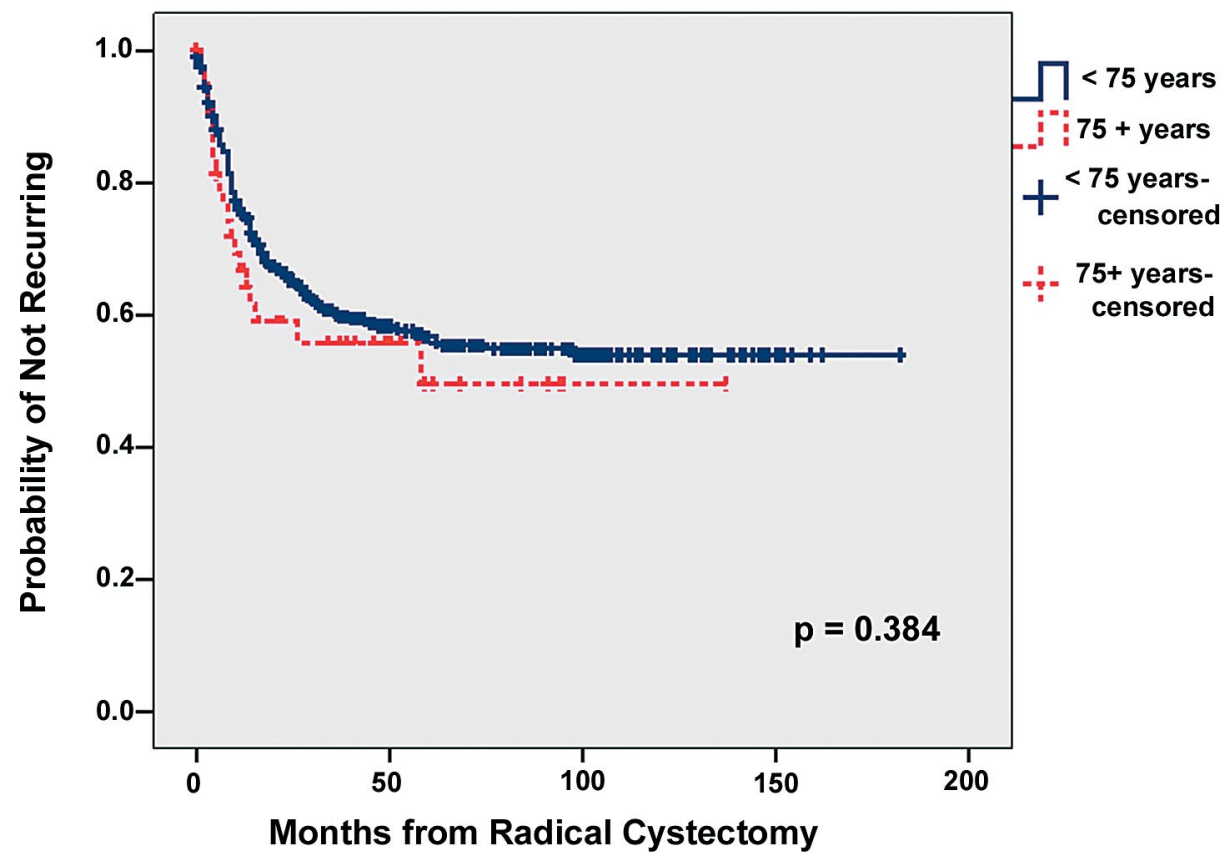

Figure 2 - Progression-free survival of 452 patients after radical cystectomy for a transitional cell carcinoma of the bladder, stratified according to age groups ( $\geq 75$ against $<75$ years, Kaplan-Meier method). 
candidates, who has an increased risk of early mortality from non-malignant associated diseases and postoperative complications. Stratification according to comorbidity provides prognostic information beyond the actual age of the patient. In this connection, the ASA score appears to be the best validated despite the inherent subjectivity of this graduation system. In a study by Malavaud et al., the ASA score was the only independent predictor for complications after RC (39). Wolters et al. showed in their study that ASA score 3 (risk ratio: 2.2) and ASA score 4 (risk ratio: 4.2) were associated with a significant increase in postoperative complications (40). Using the current data situation, it is not possible to define for patients $\geq$ 75 at which cut-off of one of the available comorbidity scores only a palliative treatment concept is justified. Future studies must also evaluate the functional status of the elderly based on a geriatric assessment.

On elderly patients with $\mathrm{RC}$, the validation of optimized pre, intra and postoperative phases for improving patient outcome is undisputed. For our patients, we implement effective intestinal preparation with fluid substitution to prevent dehydration, preoperative cardiac protection through medication with beta blockers (41), careful surgical technique, intensive intraoperative monitoring, and intensive breathing exercises with early mobilization and early reintroduction of food are decisive aspects for minimizing morbidity (42).

In our study, age had no significant influence on the pathological stage of the tumor, progressionfree survival and overall survival; the differences between Groups- 1 and 2 were only tendentious and not significant in the 3 criteria. It can be concluded from this that due to RC, patients $\geq 75$ similarly need to be effectively treated and benefit to an identical extent from definitive surgery as younger patients. The virtually identical total survival rate indicates that survival of elderly patients is primarily determined by the cancer and, presuming careful patient selection, possible comorbidity is only of subordinate importance here. By contrast, the results of Clark et al., indicate that patients over 80 had a lower total survival and also progression-free survival than younger patients after RC (33). When evaluating the 12-year data (1988-1999) of the National Cancer Institute's Sur- veillance, Epidemiology and Results, Hollenbeck et al., came to the conclusion that patients over 80 also benefit from aggressive treatment, provided an indication for this can be derived from their tumor stage. It must however be pointed out that of the 3,354 patients in this age group, only $11.5 \%$ were treated by cystectomy (43).

Some limitations of the study have to be pointed out. First of all, it mainly represents a retrospective collection of every day practice at three municipal hospitals with 44 elderly patients $(9.7 \%$ of all cases) stretched out in a 12 years period. The number and amplitude of critical variables (perioperative management, differences in follow-up time between the groups) makes it quite difficult to draw conclusions. Secondly, the discussion about the definition of a high volume cystectomy center is still open and not part of our study. The data in this context are very conflicting. Hollenbeck et al. postulate a limit of 14 radical cystectomies per annum and department (44). Linda Elting from Anderson Cancer Center in Houston / Texas defines the groups low, moderate and high volume center as $\leq 3$ per year, $4-10$ per year and $\geq$ 10 radical cystectomies per year (45). That would mean that we have evaluated one moderate and two high volume centers. Nevertheless we currently do not intend to join this case number discussion. In Germany there are still considerable differences concerning technical and personal equipment between urological departments in university hospitals, municipal hospitals (as evaluated here) and smaller peripheral hospitals. All of the currently available studies concerning the question whether radical cystectomy is reasonable in elderly patients originate from university hospitals. Hence we regard the question raised by our study as extremely important, as well we record the first non-university data on this scale concerned with that subject.

Radical cystectomy with urinary diversion is a safe and effective form of treatment for elderly patients with invasive bladder cancer. The procedure can also be carried out in patients $\geq 75$ with low perioperative mortality and acceptable morbidity at municipal hospitals. The precondition for this is a careful preoperative patient selection, which should be based on the cardio pulmonary status, the ASA score 
and possibly the geriatric assessment. Since the survival rate of younger and older patients does not differ significantly in this study, we conclude that patients $\geq 75$ can be similarly effectively treated by RC and can benefit to an identical extent as younger patients from definitive surgery.

\section{CONFLICT OF INTEREST}

None declared.

\section{REFERENCES}

1. Krege S, Friedrich C, Lummen G, Pientka L, Rubben H: Geriatric assessment. Is it significantly helpful in selection of elderly tumour patients for a difficult therapy? Urologe A. 2004; 43: 922-9.

2. Botteman MF, Pashos CL, Redaelli A, Laskin B, Hauser $\mathrm{R}$ : The health economics of bladder cancer: a comprehensive review of the published literature. Pharmacoeconomics. 2003; 21: 1315-30.

3. Quek ML, Stein JP, Daneshmand S, Miranda G, Thangathurai D, Roffey P, et al.: A critical analysis of perioperative mortality from radical cystectomy. J Urol. 2006; 175: 886-9; discussion 889-90.

4. Knap MM, Lundbeck F, Overgaard J: Early and late treatment-related morbidity following radical cystectomy. Scand J Urol Nephrol. 2004; 38: 153-60.

5. Stein JP, Lieskovsky G, Cote R, Groshen S, Feng AC, Boyd S, et al.: Radical cystectomy in the treatment of invasive bladder cancer: long-term results in 1,054 patients. J Clin Oncol. 2001; 19: 666-75.

6. Coebergh JW, Janssen-Heijnen ML, Post PN, Razenberg PP: Serious co-morbidity among unselected cancer patients newly diagnosed in the southeastern part of The Netherlands in 1993-1996. J Clin Epidemiol. 1999; 52: 1131-6.

7. Peyromaure M, Guerin F, Debre B, Zerbib M: Surgical management of infiltrating bladder cancer in elderly patients. Eur Urol. 2004; 45: 147-53; discussion 154.

8. Kursh ED, Rabin R, Persky L: Is cystectomy a safe procedure in elderly patients with carcinoma of the bladder? J Urol. 1977; 118: 40-2.

9. Zingg EJ, Bornet B, Bishop MC: Urinary diversion in the elderly patient. Eur Urol. 1980; 6: 347-51.

10. Zincke H: Cystectomy and urinary diversion in patients eighty years old or older. Urology. 1982; 19: 139-42.
11. Thomas DM, Riddle PR: Morbidity and mortality in 100 consecutive radical cystectomies. Br J Urol. 1982; 54:716-9.

12. Drago JR, Rohner TJ Jr: Cystectomy and urinary diversion: a safe procedure for elderly patients. Urology. 1983;21:17-9.

13. Tachibana M, Deguchi N, Jitsukawa S, Murai M, Nakazono M, Tazaki H: One-stage total cystectomy and ileal loop diversion in patients over eighty years' old with bladder carcinoma. Pre- and postoperative functional reserve of various organs. Urology. 1983; 22:512-6.

14. Skinner EC, Lieskovsky G, Skinner DG: Radical cystectomy in the elderly patient. J Urol. 1984; 131: 1065-8.

15. Ogawa A, Yanagisawa Y, Nakamoto T, Wajiki M, Hirabayashi N, Nakama M: Treatment of bladder carcinoma in patients more than 80 years old. J Urol. 1985; 134: 889-91.

16. Wood DP Jr, Montie JE, Maatman TJ, Beck GJ: Radical cystectomy for carcinoma of the bladder in the elderly patient. J Urol. 1987; 138: 46-8.

17. Orihuela E, Cubelli V: Management and results in elderly patients with urologic cancer. Semin Urol. 1987; 5: 134-40.

18. Bollack C, Jacqmin D, Cuvelier G, Bertrand P: Radical cystectomy in patients over 70 years. Prog Clin Biol Res. 1989; 303: 613-6.

19. Leibovitch I, Avigad I, Ben-Chaim J, Nativ O, Goldwasser B: Is it justified to avoid radical cystoprostatectomy in elderly patients with invasive transitional cell carcinoma of the bladder? Cancer. 1993; 71:3098-101.

20. Navon JD, Wong AK, Weinberg AC, Ahlering TE: A comparative study of postoperative complications associated with the modified Indiana pouch in elderly versus younger patients. J Urol. 1995; 154: 1325-8.

21. Koch MO, Smith JA Jr: Influence of patient age and co-morbidity on outcome of a collaborative care pathway after radical prostatectomy and cystoprostatectomy. J Urol. 1996; 155: 1681-4.

22. Stroumbakis N, Herr HW, Cookson MS, Fair WR: Radical cystectomy in the octogenarian. J Urol. 1997; 158: 2113-7.

23. Figueroa AJ, Stein JP, Dickinson M, Skinner EC, Thangathurai D, Mikhail MS, et al.: Radical cystectomy for elderly patients with bladder carcinoma: an updated experience with 404 patients. Cancer. 1998; 83: 141-7.

24. Rosario DJ, Becker M, Anderson JB: The changing pattern of mortality and morbidity from radical cystectomy. BJU Int. 2000; 85: 427-30. 
25. Lance RS, Dinney CP, Swanson D, Babaian RJ, Pisters LL, Palmer LJ, et al.: Radical cystectomy for invasive bladder cancer in the octogenarian. Oncol Rep. 2001; 8: 723-6.

26. Chang SS, Alberts G, Cookson MS, Smith JA Jr: Radical cystectomy is safe in elderly patients at high risk. J Urol. 2001; 166: 938-41.

27. Game X, Soulie M, Seguin P, Vazzoler N, Tollon C, Pontonnier F, et al.: Radical cystectomy in patients older than 75 years: assessment of morbidity and mortality. Eur Urol. 2001; 39: 525-9.

28. Saika T, Suyama B, Murata T, Manabe D, Kurashige T, Nasu Y, et al.: Orthotopic neobladder reconstruction in elderly bladder cancer patients. Int J Urol. 2001; 8: 5338.

29. Gschwend JE, Hautmann RE, Volkmer BG: Radical cystectomy and urinary diversion in elderly patients with increased comorbidity. Urologe A. 2004; 43: 930-4.

30. Gupta NP, Goel R, Hemal AK, Dogra PN, Seth A, Aron $\mathrm{M}$, et al.: Radical cystectomy in septuagenarian patients with bladder cancer. Int Urol Nephrol. 2004; 36 : 353-8.

31. Deliveliotis C, Papatsoris A, Chrisofos M, Dellis A, Liakouras C, Skolarikos A: Urinary diversion in highrisk elderly patients: modified cutaneous ureterostomy or ileal conduit? Urology. 2005; 66: 299-304.

32. Zebic N, Weinknecht S, Kroepfl D: Radical cystectomy in patients aged $>$ or $=75$ years: an updated review of patients treated with curative and palliative intent. BJU Int. 2005; 95: 1211-4.

33. Clark PE, Stein JP, Groshen SG, Cai J, Miranda G, Lieskovsky G, et al.: Radical cystectomy in the elderly: comparison of clincal outcomes between younger and older patients. Cancer. 2005; 104: 36-43.

34. AJCC: Cancer Staging Manual (6 ed.), Philadelphia, Lippincott-Raven. 2002.

35. Aronson WL, McAuliffe MS, Miller K: Variability in the American Society of Anesthesiologists Physical Status Classification Scale. AANA J. 2003; 71: 265-74.
36. Krege S, Friedrich C, Pientka L, Rubben H: Geriatric urology — tumour diseases. Aktuelle Urol. 2006; 37 : 45-51.

37. Dibert C: Delirium and the older adult after surgery. Perspectives. 2004; 28: 10-6.

38. Charlson ME, Pompei P, Ales KL, MacKenzie CR: A new method of classifying prognostic comorbidity in longitudinal studies: development and validation. J Chronic Dis. 1987; 40: 373-83.

39. Malavaud B, Vaessen C, Mouzin M, Rischmann P, Sarramon J, Schulman C: Complications for radical cystectomy. Impact of the American Society of Anesthesiologists score. Eur Urol. 2001; 39: 79-84.

40. Wolters U, Wolf T, Stutzer H, Schroder T: ASA classification and perioperative variables as predictors of postoperative outcome. Br J Anaesth. 1996; 77: 217-22.

41. Mangano DT, Layug EL, Wallace A, Tateo I: Effect of atenolol on mortality and cardiovascular morbidity after noncardiac surgery. Multicenter Study of Perioperative Ischemia Research Group. N Engl J Med. 1996; 335: 1713-20. Erratum in: N Engl J Med 1997; 336: 1039.

42. Knap MM, Lundbeck F, Overgaard J: Early and late treatment-related morbidity following radical cystectomy. Scand J Urol Nephrol. 2004; 38: 153-60.

43. Hollenbeck BK, Miller DC, Taub D, Dunn RL, Underwood W 3rd, Montie JE, et al.: Aggressive treatment for bladder cancer is associated with improved overall survival among patients 80 years old or older. Urology. 2004; 64: 292-7.

44. Hollenbeck BK, Daignault S, Dunn RL, Gilbert S, Weizer AZ, Miller DC: Getting under the hood of the volumeoutcome relationship for radical cystectomy. J Urol. 2007; 177: 2095-9; discussion 2099.

45. Elting LS, Pettaway C, Bekele BN, Grossman HB, Cooksley C, Avritscher EB, et al.: Correlation between annual volume of cystectomy, professional staffing, and outcomes: a statewide, population-based study. Cancer. 2005; 104: 975-84.

\author{
Correspondence address: \\ Dr. Matthias May \\ Department of Urology \\ Carl-Thiem Hospital Cottbus \\ University Teaching Hospital, Charité zu Berlin \\ Thiemstrasse 111, D-03048 Cottbus, Germany \\ Fax: + 49355-462053 \\ E-mail:m.may@ctk.de
}

Accepted after revision:

July 18, 2007 


\section{EDITORIAL COMMENT}

This study addresses the results of radical cystectomy and urinary diversion for bladder cancer, focusing on elderly patients. A description of peri-operative morbidity and mortality is given, comparing the group of patients aged 75 years or older, to the group of patients aged less than 75 years. Data was acquired over more of a decade of activity, at three different Community Hospitals in Germany. The oncological outcome of the series of patients under study is also reported.

The study addresses an undoubtedly interesting issue, and represents an honest account of everyday practice. Within the limitations properly acknowledged by the authors, mainly consisting in the retrospective nature of the report with the lack of a preset, systematic approach, this appears as an altogether informative study, worth of some reflections.

Our understanding of radical cystectomy for bladder cancer is based mainly on the reports from major referral centers which, as a matter of fact, may not reflect the general standard approach to bladder cancer, since there is evidence that radical cystectomy is under-performed, especially so in the elderly, even within particularly developed health-care systems $(1,2)$.

The need for re-do surgery in this study was a sober $5.3 \%$, that is, objectively low. I believe this data, as well as others - i.e. medical complications, length of stay, employment of medical resources, etc. - should find a place in the issue of case-loads, and be used as indicators of health-care quality, alongside with the mere assessment of "volume". The central information of this series from three Community Hospitals is that radical cystectomy is safe and effective in providing control of bladder cancer, and it is consistent with the observations derived from major referral centers.

In recent years, a more comprehensive knowledge of peri-operative pathophysiology coupled with the effort of enhancing the postoperative recovery of organ functions has led to the implementation of a multimodality peri-operative approach, namely, the socalled fast track surgery. Such novel approach has affected significantly on the postoperative course of abdominal surgery (3), and is currently being introduced in urology, specifically for radical cystectomy (4). Probably, this would contribute to expand further the diffusion of radical cystectomy in bladder cancer patients, including the elderly.

\section{REFERENCES}

1. Konety BR, Joslyn SA: Factors influencing aggressive therapy for bladder cancer. An analysis of data from the SEER programme. J Urol. 2003; 170: 1765-71.

2. Prout GR, Wesley MN, Yancik R, Ries LA, Havlik RJ, Edwards BK: Age and comorbidity impact surgical therapy in older bladder carcinoma patients: a population based study. Cancer. 2005; 104: 1638-47.

3. Kehlet H, Dahl JB: Anaesthesia, surgery and challenges for postoperative recovery. Lancet. 2003; 362: 19211928.

4. Maffezzini M, Gerbi G, Campodonico F, Parodi D: Multimodal peri-operative plan for radical cystectomy and intestinal urinary diversion. I. Effect on the recovery of intestinal function and occurrence of complications. Urology. 2007; 69: 1107-11.

Dr. Massimo Maffezzini

Head of Urology Unit

Chief, Department of Specialised Surgery

Ospedali Galliera

Genoa, Italy

E-mail: massimo.maffezzini@galliera.it 


\section{EDITORIAL COMMENT}

Population with longer life expectancy increase continuously not only in developed countries but also in many other less developed countries. It means that in the future surgical intervention such as radical cystectomy (RC) with urinary diversion which is the standard treatment for muscle invasive bladder cancer will be more common in elderly.

The authors comprehensively evaluated their experience in RC on patients' $\geq 75$ years in municipal hospital. This is an important point because according to the standard in Germany, municipal hospital will have less (advanced) technical equipment as well as medical personnel number compared to university hospital. With careful preoperative patient evaluation and selection as well as well-planned perioperative care their results support other reports in regard of similar complication and survival between elderly and younger patients.

\section{EDITORIAL COMMENT}

The authors compare complication and survival rates of patients older than 74 years following cystectomy for bladder cancer with younger patients. The study population is recruited from three urological departments at municipal hospitals. As mentioned by the authors, numerous studies in university hospitals exist, and all show that the outcome in older patients is no worse than in younger patients. It is stated that the main difference of the current study compared to existing literature is the fact that their patients were operated at municipal hospitals without a high volume of cystectomies.
Almost half of their patients receive orthotopic ileal neobladder which is considered will prolong the operative time. However, as stated by the authors, with effective prevention of dehydration and perioperative care, the morbidity could be minimized. Huang \& Stein (1) reported that the most common early complication was related to dehydration whereas only $15 \%$ related to urinary diversion.

This information could encourage other urologist who works with limited resources to perform RC as long as with strict selection criteria and well planned perioperative care.

\section{REFERENCE}

1. Huang GJ, Stein JP: Open radical cystectomy with lymphadenectomy remains the treatment of choice for invasive bladder cancer. Curr Opin Urol. 2007; 17: 36975.

Dr. Rainy Umbas

University of Indonesia

Faculty of Medicine, Division of Urology

Jakarta, Indonesia

E-mail: rainyu@rad.net.id

Several studies have clearly indicated a relationship between hospital and/or surgeon volume and outcomes from treatment (medical or surgical) from various diseases (1). Birkmeyer et al. (2) reported a decreased postoperative mortality rate following radical cystectomy for bladder cancer at very high volume hospitals ( $>11$ cases/year) compared with the rate of very low volume hospitals ( $<2$ cases/ year), using information from the national Medicare claims data base and the Nationwide Inpatient Sample in the United States. In another study, the same investigator found that the surgeon volume 
accounted for a large proportion of the apparent effect of hospital volume, which was 39\% for radical cystectomy (3). Using the Health Care Utilization Project-Nationwide Inpatient Sample, Konety et al. (4) also demonstrated a significant effect of hospital volume (low volume $<1.5$ cases/year, moderate volume $1.5-2.75$ cases/year, high volume $>2.75$ cases/ year) on postoperative mortality after radical cystectomy. Furthermore, it was shown in this study that the effect of hospital volume was greatest in older patients. Elting et al (Ref. 45 in the article) used data from the Texas Hospital Discharge Public Use Data File, indicating that the mortality following cystectomy in high volume hospitals (> 10 cases/year) is significantly lower. All of these studies obtained their data from national/statewide databases including all types of hospitals.

According to the above-mentioned definitions, the three municipal hospitals in this study are high/ moderate volume centers. Therefore, these results are a further contribution to the growing body of evidence on the impact of high volume hospitals and surgeons on patients' outcome. The type of hospital is obviously less important.

\section{REFERENCES}

1. Halm EA, Lee $\mathrm{C}$, Chassin MR: Is volume related to outcome in health care? A systematic review and methodologic critique of the literature. Ann Intern Med. 2002; 137:511-20.

2. Birkmeyer JD, Siewers AE, Finlayson EV, Stukel TA, Lucas FL, Batista I, et al.: Hospital volume and surgical mortality in the United States. N Engl J Med. 2002; 346: 1128-37.

3. Birkmeyer JD, Siewers AE, Goodney PP, Wennberg DE, Lucas FL.: Surgeon volume and operative mortality in the United States. N Engl J Med. 2003; 349: 2117-27.

4. Konety BR, Dhawan V, Allareddy V, Joslyn SA: Impact of hospital and surgeon volume on in-hospital mortality from radical cystectomy: data from the health care utilization project. J Urol. 2005; 173: 1695-700.

Dr. Joerg Simon Department of Urology University of Ulm Ulm, Germany E-mail: joerg.simon@uniklinik-ulm.de 